\title{
Chapter 12 \\ Inequalities in the Impact of the Carbon Tax in Japan
}

\author{
Nozomu Inoue, Shigeru Matsumoto, and Minoru Morita
}

\begin{abstract}
Although Japan's current carbon tax rate is much lower than the rates applied in European countries, the Japanese government may increase the tax rate in the near future, in order to strengthen measures to combat global warming. Since a country's carbon-pricing policy does not distort its economy, it is considered to be an efficient policy measure. However, the burden of carbon pricing varies across regions and across households. Since low-income households generally allocate a larger proportion of their disposable income to energy costs than high-income households, the burden of carbon taxes on low-income households tends to be higher than for high-income households. In addition, households in cold regions spend more money for space heating, and those in rural areas spend more money for gasoline. Unless the government objectively analyzes the impact of carbon pricing and proposes convincing countermeasures to deal with these unequal impacts, the government is unlikely to obtain public support for a carbon tax increase. In this study, we analyze microlevel data from the Japanese National Survey of Family Income and Expenditure (NSFE) collected from 1989 to 2014, and examine how past energy price changes affected the welfare of different types of households. We then propose countermeasures to address the problems arising from the regressive nature of taxing energy use.
\end{abstract}

Keywords Distributional impacts · Japanese national survey of family and expenditure $\cdot$ Welfare

This work was supported by JSPS KAKENHI Grant Numbers 18K01578.

N. Inoue

National Institute of Population and Social Security Research, Tokyo, Japan

S. Matsumoto $(\bowtie)$

Faculty of Economics, Aoyama Gakuin University, Room 828, Building 8, 4-4-25 Shibuya,

Shibuya, Tokyo 150-8366, Japan

e-mail: shmatsumoto@ aoyamagakuin.jp

M. Morita

Faculty of Regional Policy, Takasaki City University of Economics, Takasaki City, Gunma, Japan

(C) The Author(s) 2021

T. H. Arimura and S. Matsumoto (eds.), Carbon Pricing in Japan,

Economics, Law, and Institutions in Asia Pacific,

https://doi.org/10.1007/978-981-15-6964-7_12 


\section{Introduction}

Although carbon taxes were introduced in European countries in the early 1990s, the Japanese government spent a quarter century debating the issue until finally introducing a carbon tax, refered as "global warming countermeasure tax (Chap. 1)", in 2012. The present carbon tax rate in Japan is very low, equal to USD 2.63 per $\mathrm{CO}_{2}$ ton, which correspond to USD 0.007 per kilo liter of gasoline, USD 0.007 per liter of kerosene, and USD 0.001 per kWh of electricity, which is much lower rates observed in European countries (Cabinet Office of Japan 2009). According to estimates by the Ministry of the Environment (2012), the burden of the new carbon tax remains at USD 11.2 per year on the average household in Japan.

Prior to introducing the new carbon tax, various energy taxes had been imposed in Japan. Both a crude oil tariff (USD 0.0015 per liter) and a petroleum coal tax (USD 0.019 per liter) are levied on energy imports. At the sales stage, energy taxes are imposed on gasoline (USD 0.49 per liter), diesel oil (USD 0.29 per liter), jet fuel (USD 0.24 per liter), and LP gas (USD 0.09 per liter), in addition to a consumption $\operatorname{tax}(5 \%) .{ }^{1}$ Even if the "effective carbon rate" that includes the above-mentioned energy-related taxes is used, the tax rate in Japan is still lower than the rates in many European countries. For instance, gasoline and diesel fuel taxes in Germany are USD 0.83 and USD 0.60 per liter, respectively (Cabinet Office of Japan 2009). Despite the large differences in tax rates between Japan and European countries, there is no significant difference in the retail energy prices that households actually pay. This is due to the large difference in energy prices before taxation (see Sect. 3 for more detail).

One of the major differences between the new carbon tax introduce in 2012 and the energy taxes which existed before its introduction would be the consideration of the energy use purpose. Energy use purposes are considered in Japan's existing energy taxes, as the rates are differentiated according to energy use purposes. In contrast, energy use purposes are not a factor in the carbon tax; the tax rates are simply based on a $\mathrm{CO}_{2}$ basis. Therefore, the new carbon tax is economically more efficient than the existing approach. On the other hand, the new carbon tax would impose different burdens across regions and households. Households living in cold regions spend substantially more money for heating than households in warmer areas, as the energy bill must be paid even if prices increase since heating is an essential service in winter time. Private motor vehicles are used intensively in rural areas where public transportation networks are inadequate. Consequently, households in rural areas consume more gasoline than those in urban and suburban areas. However, if gasoline prices were to increase due to a carbon tax without an increase in alternative transportation services, the mobility of rural households will be restricted. Low-income households generally allocate a larger proportion of their disposable income to energy services than high-income households. Thus, if the carbon tax is increased, the tax burden will tend to fall disproportionately on low-income households compared to high-income households. In addition, even though certain energy

\footnotetext{
${ }^{1}$ The consumption tax rate is $10 \%$ in 2020 .
} 
services are required to live a normal life, a carbon tax increase could make such energy services unaffordable for low-income households.

In order to gain public support for a higher carbon tax, the government would have to propose convincing countermeasures to mitigate the regressive nature of a carbon tax. To propose feasible and convincing countermeasures, we need to understand how much energy different types of households use as well as for what purposes they use energy. The purpose of this study is to analyze household energy consumption data over the last 25 years and to propose countermeasures to mitigate the regressive nature of a carbon tax.

For this analysis, we use micro-level data from Japan's National Survey of Family Income and Expenditure (NSFIE). In Sect. 2, we explain our data construction. Households use various types of energy and their usage patterns have changed over time. In Sect. 3, we report historical changes in household energy consumption. We also examine how the pattern of energy consumption also varies across regions. For example, households in colder regions use energy differently than households in warmer regions. Finally, previous studies reveal that household characteristics affect energy usage patterns, so Sect. 3 also examines family composition, age of the head of household, and household income. We also examine how these household characteristics are related to household energy consumption. Our data analyses reveal a considerable variation in the pattern of energy consumption across regions as well as across households, and how large the difference in the tax burden can be across households. In Sect. 4, we make policy proposals to mitigate the regressive nature of the carbon taxation.

\section{Data}

Our primary data source is Japan's National Survey of Family Income and Expenditure (NSFIE) for 1989, 1994, 1999, 2004, 2009, and 2014 (Statistics Bureau of Japan Statistical Bureau of Japan 1989a-2018a). The NSFIE is a nationwide cross-sectional survey that was initiated in 1959 is conducted every five years. Each survey covers more than 55,000 households that are asked about their expenditures for electricity, city gas, gasoline, kerosene, and propane gas use from September to November.

Energy prices vary between regions and over time. We identify the location of each household surveyed in the NSFIE and obtain the energy prices that household faced from the Retail Price Survey provided by Statistics Bureau of Japan (1989-2014b). By dividing the expenditure by these energy prices, we calculate the energy consumption for each household in the appropriate unit of measure, such as $\mathrm{kWh}$, liter, and $\mathrm{m}^{3}$.

Although gasoline, kerosene, and propane gas are sold by volume, electricity and city gas have a "base charge" that does not depend on usage and a "meter charge" that increases with usage. Moreover, block pricing is applied for the meter charge. 


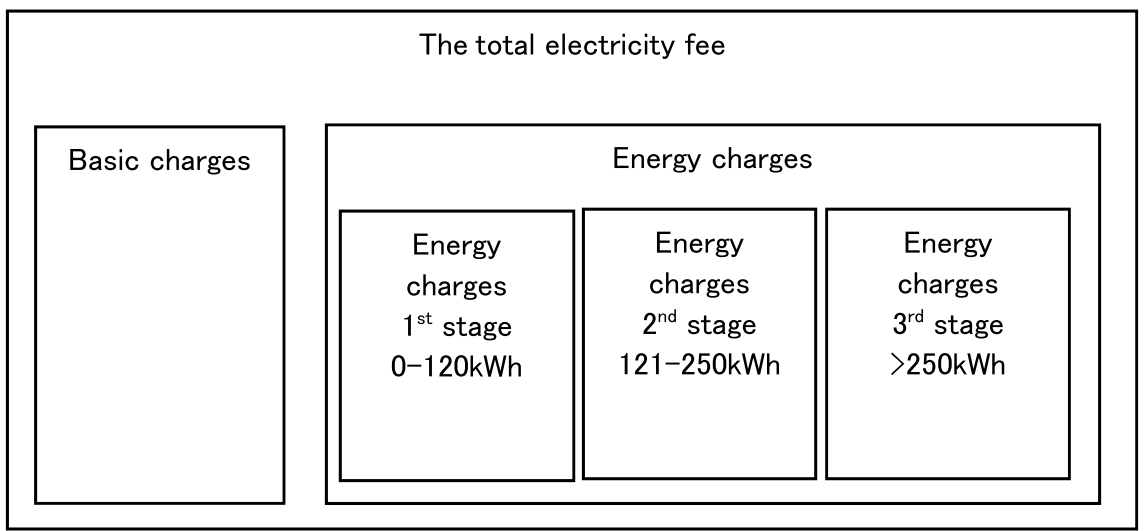

Fig. 1 An example of electric pricing scheme

Figure 1 is an example of the block pricing from the Retail Price Survey in 1989 and $1994 .^{2}$

In the first block, from 1 to $120 \mathrm{kWh}$, the lowest unit price was charged. In the second block, from 121 to $250 \mathrm{kWh}$, the unit price is higher than in the first block. The maximum unit price is charged if monthly electricity consumption is greater than $250 \mathrm{kWh}$. We account for the price variation in the block pricing scheme in estimating electricity consumption for each household. ${ }^{3}$

Next, we converted the energy consumption based on physical units to energy units (mega joules (MJ)), using the Fact-finding Survey on Estimation of Carbon Dioxide Emissions from Homes by the Ministry of the Environment Japan (see appendix for details).

Figure 2 shows the change in total energy consumption for the average household

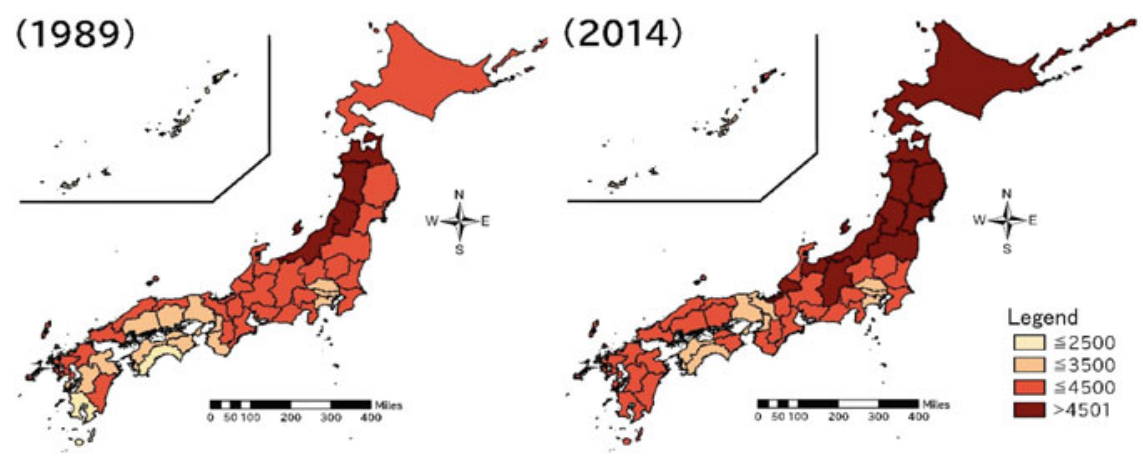

Fig. 2 The change in the total energy consumption

\footnotetext{
${ }^{2}$ The threshold value in block pricing has been changed since 1999 .

${ }^{3}$ We made seasonal adjustments for the CPI time series data.
} 


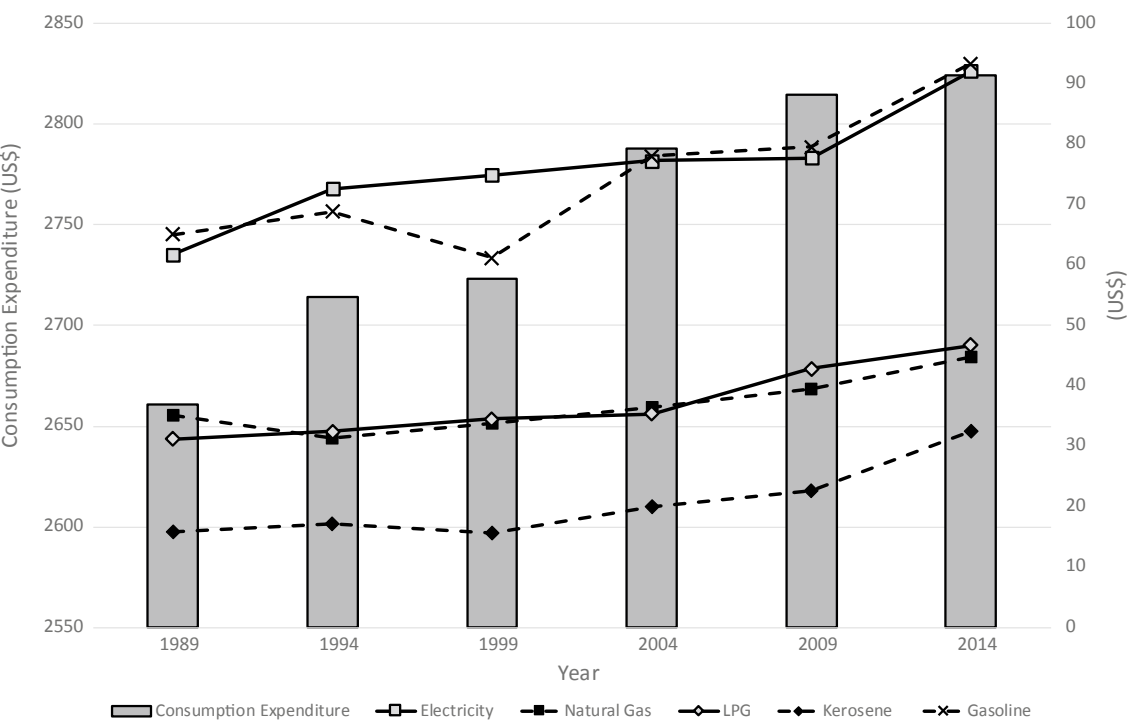

Fig. 3 Historical change in household energy expenditures Source "Consumption Expenditure" from Family Income and Expenditure Survey (Ministry of Internal Affairs and Communications), "Electricity", "Natural Gas", "LPG", "Kerosene" and "Gasoline" from NSFIE. Note 1. "Consumption Expenditure" is the average per month for all worker-households. Note 2. Using the 2011 GDP deflator, we initially convert all nominal values into real values. We then convert Japanese yen into US dollars, assuming that one USD is equivalent to 110 yen

in each prefecture in Japan from 1989 to 2014. The figure clearly shows that overall energy consumption increased from 1989 to 2014.

\section{Analysis}

\subsection{Historical Changes in Household Energy Expenditure}

Figure 3 shows the historical changes in monthly consumption expenditures of all worker-households and the expenditures for each type of energy (electricity, city gas, LP gas, kerosene, and gasoline). Total monthly expenditures are shown by the bars in the graph and are measured on the left vertical axis. The expenditures for each type of energy are shown by the lines and are measured on the right vertical axis.

The line graphs show that all energy expenditures increased over the sampling period. ${ }^{4}$ The figure further shows that expenditures for electricity and gasoline were two to three times greater than for other types of energy throughout the sampling

\footnotetext{
${ }^{4}$ Even when the data are broken down by region, we confirm that monthly energy expenditures increased in all regions.
} 
period. ${ }^{5}$ This reflects the fact that as the Japanese economy has matured, many households own and use a greater variety of electric appliances (e.g. air conditioners, refrigerators, and TVs, etc.) and own private automobiles. Taking a closer look at the changes in the expenditure for each type of energy, we find that expenditures for kerosene increased by 2.1 times from 1989 to 2014, while expenditures for electricity, city gas, and gasoline increased about 1.5 times and expenditures for LP gas increased about 1.3 times.

As shown by the bar graph, monthly total expenditures for the average Japanese household increased only 1.1 times from 1989 to 2014, due to sluggish growth after the end of the bubble economy. However, despite slowing growth in overall spending, Japanese households did not reduce energy expenditures and still spend a substantial amount of money on electricity and gasoline; the average household spends about USD 60-90 per month. This amount is much larger than the amount spent for city gas, LP gas, and kerosene; the expenditures for those energies are about USD 15-45 per month. These facts suggest that the expenditures for electricity have been becoming relatively more important for Japanese households in recent years.

\subsection{Historical Change in Household Energy Consumption}

Figure 4 presents the historical changes in average monthly energy consumption for the average Japanese household, in terms of mega joules (MJ). Total energy consumption per month is represented by the bars in the graph and is measured on the right axis. Consumption for each type of energy is shown by the lines in the graph and is measured on the left axis.

The figure shows that total energy consumption increased from 1989 to 1999 , then started to decline. Specifically, total energy consumption increased by about 6\% from 1989 (7045 MJ) to 1999 (7453 MJ), then decreased to $5874 \mathrm{MJ}$ in 2014. The decrease from peak consumption in 1999 to 2014 is about a $21 \%$.

Next, we look at the line graphs to examine the consumption change by energy type. Electricity consumption has been increasing steadily since 1989; average monthly consumption was $1.086 \mathrm{MJ}$ in 1989 and rose to $1.467 \mathrm{MJ}$ in 2014, an increase of roughly 35\%. In contrast, the consumption of city gas, LP gas and kerosene decreased over the period. In particular, the decline in city gas consumption is remarkable, decreasing from $1910 \mathrm{MJ}$ in 1989 to $837 \mathrm{MJ}$ in 2014, a 56\% reduction. As for LP gas and kerosene, LP gas decreased by $28 \%$ (from $194 \mathrm{MJ}$ to $139 \mathrm{MJ}$ ), and kerosene decreased by $25 \%$ (from $1669 \mathrm{MJ}$ to $1256 \mathrm{MJ}$ ). Although gasoline consumption increased from 1989 (2187 MJ) to 2004 (2690 MJ), it then started to decline. Average monthly consumption in 2014 was $2175 \mathrm{MJ}$, a $19 \%$ reduction from 2004. These results suggest energy consumption in the household sector has been declining since the 2000s.

\footnotetext{
${ }^{5}$ In all regions, expenditures for electricity and gasoline are higher than for other types of energy. However, kerosene expenditures tend to be larger in cold regions.
} 
3000

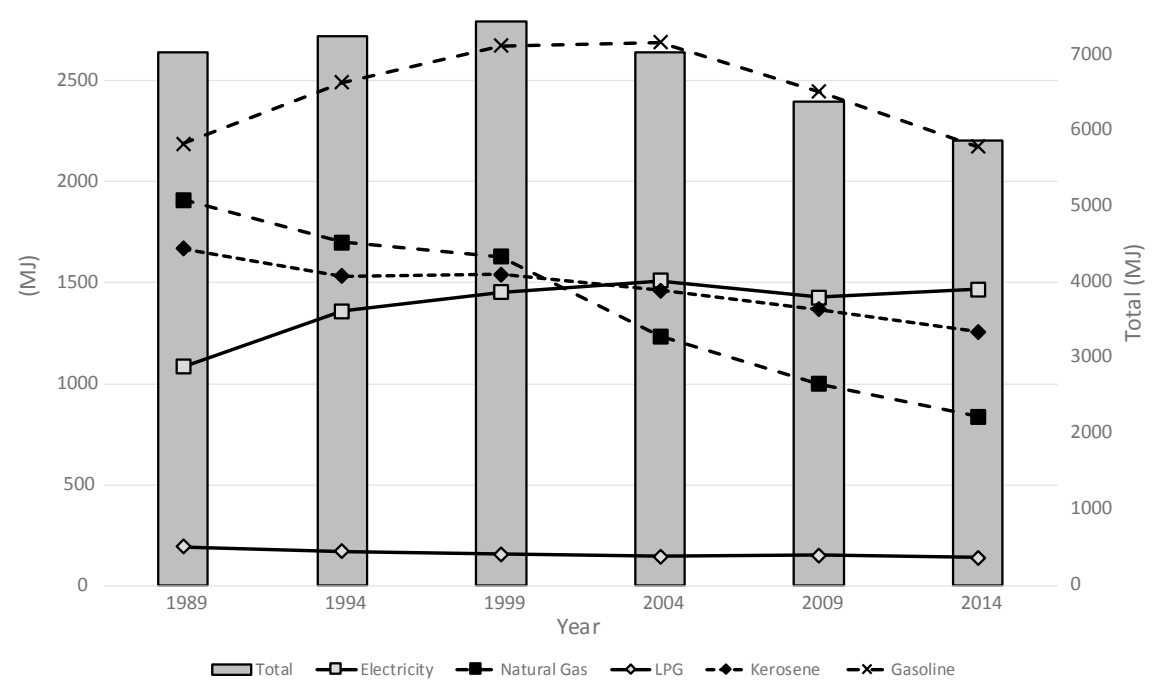

Fig. 4 Historical change in household energy consumption. Note 1 The total is the sum of consumption for all types of energy

Energy consumption is primarily affected by energy prices ${ }^{6}$ and thus it is important to know how energy prices have changed during the sample period. Below we report the historic change in energy prices in Japan.

As mentioned in Sect. 2, electricity costs for Japanese households consist of a "basic charge" and a "meter charge." To determine the basic charge, Japanese power companies use two types of systems: an ampere rating system and a basic charge system. ${ }^{7}$ In the ampere rating system, households pay a base fee according to the number of amperes contracted for with the power company. Households that want to use many appliances at once are required to contract for a higher number of amperes. In the basic charge system, households pay a minimum fixed fee regardless of their electricity consumption level. Although the lowest base fee in the ampere system and the minimum fixed fee in the basic charge system both remained between USD 2.4 and USD 3.0 during the sampling periods, since 2009 power companies have rapidly increased the unit price for electricity applied in the meter charge. ${ }^{8}$ These price increases are largely due to the rise in crude oil prices, the expansion of thermal

\footnotetext{
${ }^{6}$ All prices below, including electricity prices, have been converted to real values using a 2011-based GDP deflator. USD 1 is assumed to JPN 110.

${ }^{7}$ Hokkaido Electric Power Company, Tohoku Electric Power Company, Tokyo Electric Power Company, Hokuriku Electric Power Company, Chubu Electric Power Company, and Kyushu Electric Power Company use the ampere rating system. Kansai Electric Power Company, Chugoku Electric Power Company, Shikoku Electric Power Company, and Okinawa Electric Power Company use the basic rate system.

${ }^{8}$ Japanese electric companies are increasingly using a block pricing system, in which the unit price increases as consumption increases. For example, since 2009 Tokyo Electric Company has increased
} 
power generation caused by the shutdown of nuclear power plants after the Great East Japan (Fukishima) Earthquake in 2011, and the promotion of renewable energy sources.

Next, we summarize the changes in kerosene and gasoline prices. The price of kerosene had remained around USD 0.35 per liter from 1989 to 2004, but increased to USD 0.96 per liter between 2004 and 2014. A similar price increase was observed for gasoline prices; the gasoline price had been around USD 1.03 per liter from 1989 to 2004 , but had increased to USD 1.50 per liter by 2014. These price increases are mainly caused by increases in crude oil prices.

Finally, we look at the price changes of city gas and LP gas. The minimum or basic monthly charge for city gas had been set at less than USD 10 from 1989 to 1999, but exceeded USD 10 in the 2000s, and in 2014, the price reached to about USD 13. Although the unit price of city gas was less than USD 1 per $\mathrm{m}^{3}$ in 1999 , it was approaching USD 2 per $\mathrm{m}^{3}$ in 2014. In contrast, the price of LP gas has not changed much over the period we analyzed, remaining between USD 4.0-6.0 per $\mathrm{m}^{3}$ from 1989 to 2014.

From the analyses above, we can draw the following two important inferences. First, prices for all types of energy have been rising in recent years. Second, Japan's household sector has become increasingly dependent on electricity over the years. In 1989, the shares of electricity, city gas, kerosene, LP gas, and gasoline as a percentage of total energy consumption were $15.7 \%, 27.1 \%, 23.7 \%, 2.8 \%$, and $31.0 \%$, respectively. However, the share of electricity rose sharply to $25.0 \%$ in 2014 while the share of city gas dropped to $14.2 \%$ over that period. Clearly, Japan has already experienced a rapid household electrification but this shift is expected to further advance in the future.

\subsection{Comparison of Energy Consumption Across Regions}

We divide the country into 10 regions presented in Fig. 5 and compare monthly energy consumption for the average household across these regions in Fig. 6.9,10 Total energy consumption is shown by the bars as measured on the right vertical axis, while consumption by type of energy is shown by the line graphs, measured on the left axis.

The bars show that the region with the highest overall energy consumption was the Tohoku region, and that the average Tohoku household consumed $8452 \mathrm{MJ}$ of energy per month. Households in Hokuriku and Hokkaido regions were also high

\footnotetext{
its unit price by USD 0.02 per $\mathrm{kWh}$ in the initial block of $1-120 \mathrm{kWh}$ and by USD 0.03 per $\mathrm{kWh}$ in the block beyond $120 \mathrm{kWh}$.

${ }^{9}$ Prior to liberalization in 2016, the Japanese electricity market was a regional monopoly system. We divided the country into 10 regions on the basis of the previous monopoly system.

${ }^{10}$ The value of each type of energy consumption presented in Fig. 11.5 is the average of the monthly consumption from 1989 to 2014 for each region.
} 


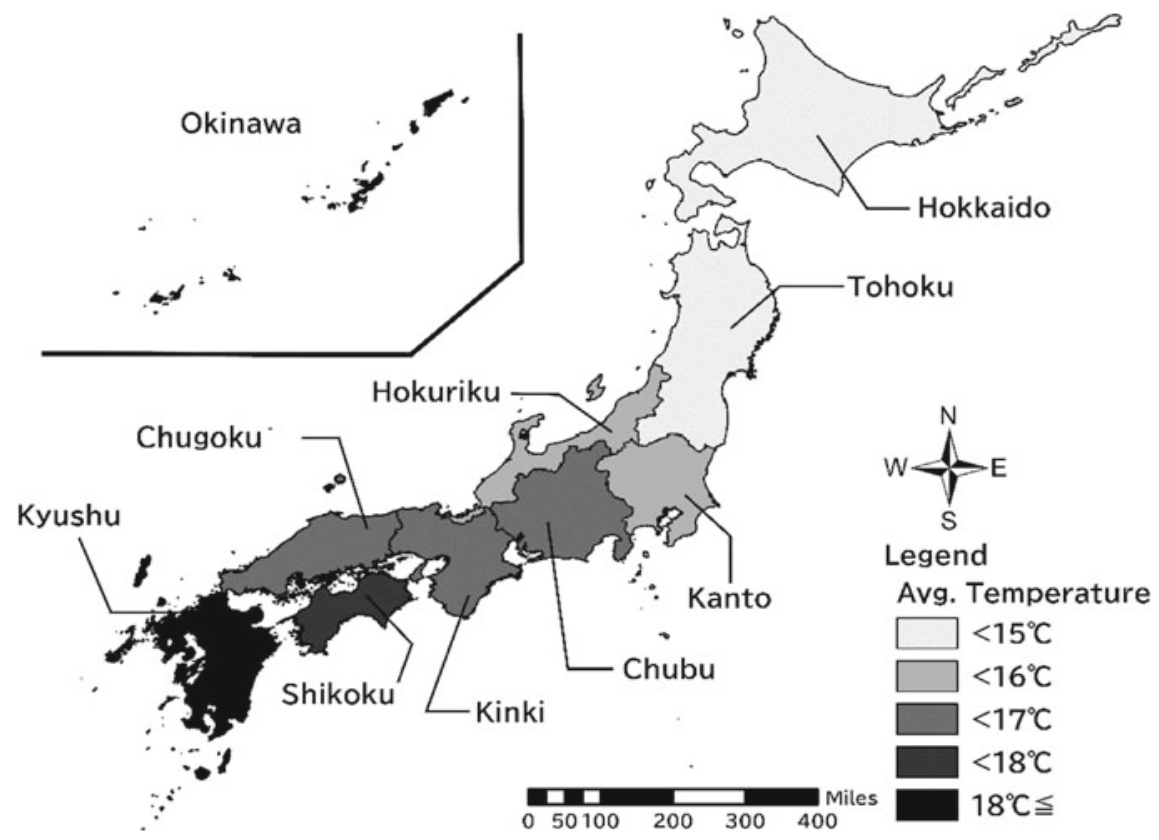

Fig. 5 Weather conditions in Japan

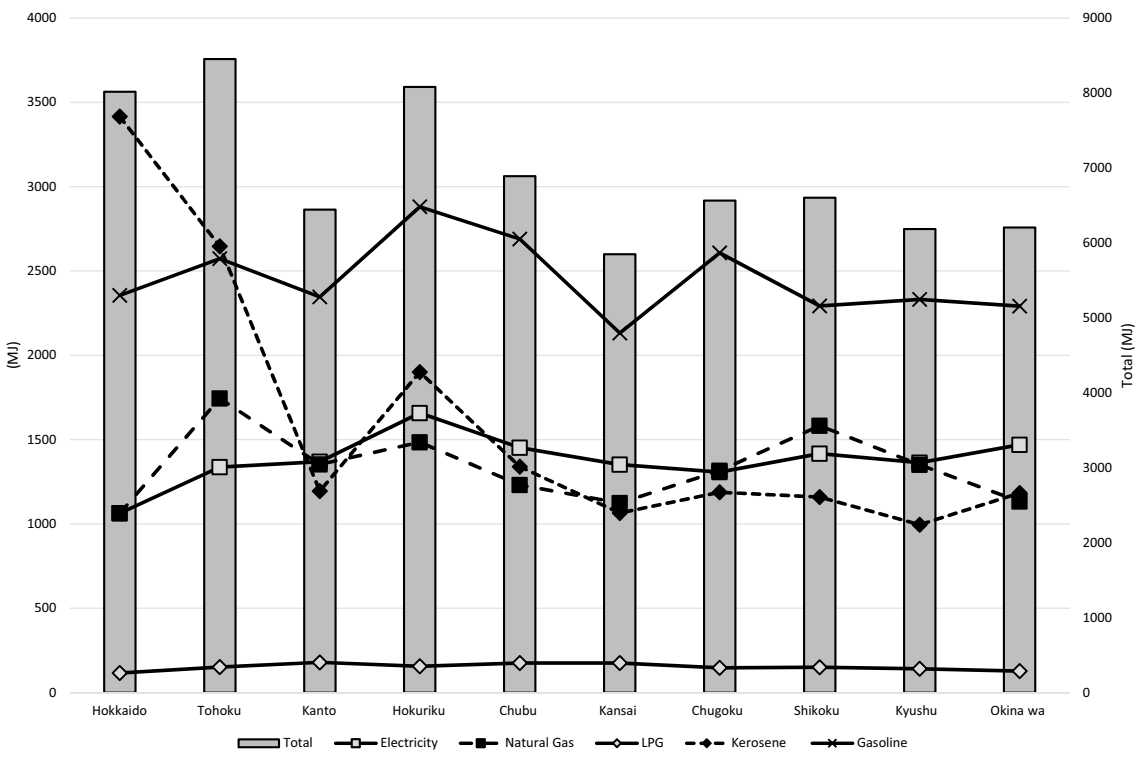

Fig. 6 Comparison of energy consumption across regions 
energy consumers; Hokuriku households consumed an average of $8081 \mathrm{MJ}$ while the Hokkaido households consumed $8016 \mathrm{MJ}$ of energy per month, on average. In contrast, the lowest energy consumption was observed in the Kansai region, where the average household consumed only $5849 \mathrm{MJ} .{ }^{11}$ We can see that, energy consumption is higher in northern regions than in southern regions, and that the difference between the two is large.

Next, we compare energy consumption across regions by type. Figure 6 shows there are large differences in kerosene consumption across regions. The Hokkaido region had the highest kerosene usage (3416 MJ), the Tohoku region consumed 2646 MJ while the Hokuriku region consumed 1901 MJ. These three regions used much larger amounts of kerosene than the other regions, most likely because these three regions are located in the northern part of Japan where temperatures throughout the year are lower than in other regions and kerosene-fueled oil stoves tend to be used more frequently for space heating. As a result, kerosene consumption accounts for $42.6 \%$ of total energy consumption in the Hokkaido region and $31.3 \%$ in the Tohoku region. These percentages are far greater than in other regions. This suggests that carbon pricing would be a significant burden to households in the northern regions since they use a large amount of kerosene for heating purposes. It is worth noting that kerosene consumption has decreased in the southern part of Japan over the last two decades and now accounts for only about $20 \%$ of total energy use.

There was no significant difference in the amount used for the remaining types of energy across regions. The highest consumption of electricity, $1658 \mathrm{MJ}$ per month, was observed in Hokuriku region, while the lowest consumption of $1064 \mathrm{MJ}$ was observed in the Hokkaido region. The relatively large electricity consumption in the Hokuriku region may be due to the relatively low cost of electricity provided by Hokuriku Power Companies, which generates much of its electricity through hydro power. The dependence on electricity as a percent of all energy sources was roughly $20 \%$ in all regions, except for Hokkaido (13.3\%) and Tohoku (15.8\%), where the large usage of kerosene makes energy consumption patterns different than the other regions.

Given the fact that many Japanese households rely heavily on electricity, it is important to know how household electricity consumption responds to changes in electricity prices. There are several studies that compare the price elasticity of household electricity demand across regions in Japan. Tanishita (2009) used electricity consumption data at the prefectural capital level from 1986 to 2006 and conducted a panel data analysis. They calculated electricity consumption by dividing the electricity bill by the unit electricity price and estimated short-run price elasticity at approximately -0.9 to -0.5 , and long-run price elasticity at about -2.7 to -1.0 . They also estimated price elasticities for each region and confirmed that Hokkaido, Tohoku, Hokuriku, Chugoku, Shikoku, and Kyushu have relatively low price elasticities, while Kanto, Kansai, and Chubu have relatively high price elasticities. Mizobata et al. (2011) used electricity consumption data for multi-person

\footnotetext{
${ }^{11}$ Households in the Kanto region, including Tokyo, used 6444 MJ, one of the lowest consumption levels.
} 
households from 1986 to 2010 and conducted a panel data analysis. They estimated the price elasticity of electricity for each power company region and reported a large variation in the price elasticity of demand for electricity across regions. They reported that short-run price elasticity ranged from -0.96 in the Hokuriku region to -0.28 in the Chubu region, while the long-run price elasticity ranged from -2.30 in the Hokuriku region to -0.95 in the Chubu region. ${ }^{12}$

Although the average price elasticity of demand for electricity in Japan as indicated in the above mentioned studies is similar to the averages found in previous studies conducted outside Japan (Espey and Espey 2004), there is a huge variation across regions within the country.

As for city gas, households in the Tohoku region consumed the greatest amount, $1744 \mathrm{MJ}$ per month, while those in the Hokkaido region consumed the lowest amount, 1064 MJ. The dependence on city gas was about $20 \%$ in all regions except in the Hokkaido region. As for LP gas, households in the Kanto region consumed the greatest amount, $180 \mathrm{MJ}$ while those in the Hokkaido region consumed the lowest amount, $116 \mathrm{MJ}$. With respect to gasoline, households in the Hokuriku region consumed the greatest amount, 2881 MJ per month, while those in the Kansai region consumed the lowest amount of gasoline, $2132 \mathrm{MJ}$ per month. There is no significant difference in LP gas or gasoline consumption between the regions; the percentage of energy consumption using LP gas is about 2-3\% while that of gasoline is about $30-40 \%$.

\subsection{Household Income and Energy Consumption}

Since household energy consumption depends not only on price but also on household income, in this sub-section we examine the relationship between household income and energy consumption. For this purpose, we classified households into seven income classes: (1) less than 2.0 million yen per year, (2) 2.0 million yen to less than 3.5 million yen, (3) 3.5 million yen to less than 5.0 million yen, (4) 5.0 million yen to less than 7.0 million yen, (5) 7.0 million yen to less than 10.0 million yen, (6) 10.0 million to less than 15 million yen, and (7) 15 million yen or more. We then calculated the monthly energy consumption of the average household in each income category. Income distribution among Japanese households is presented in Fig. 7.

Figure 8 shows the monthly energy consumption in each income category. ${ }^{13}$ Total energy consumption is presented by the bars and is measure on the right axis, and energy consumption per type of energy is presented by the lines, measured on the left axis.

\footnotetext{
${ }^{12}$ The estimated price elasticity is similar to findings in studies conducted in other countries (Espey and Espey 2004; Narayana et al. 2007; Krishnamurthy and Kriström 2015).

${ }^{13}$ The energy consumption presented in Fig. 11.6 is the monthly energy consumption averaged over between 1989 and 2014 .
} 


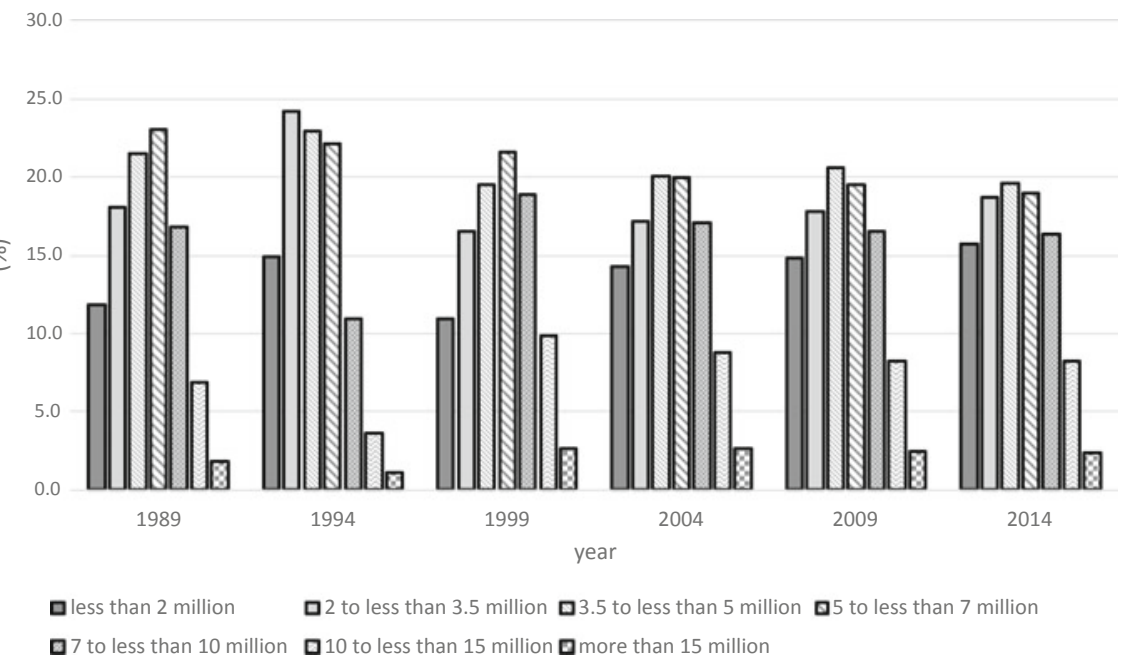

Fig. 7 Income distribution among Japanese households

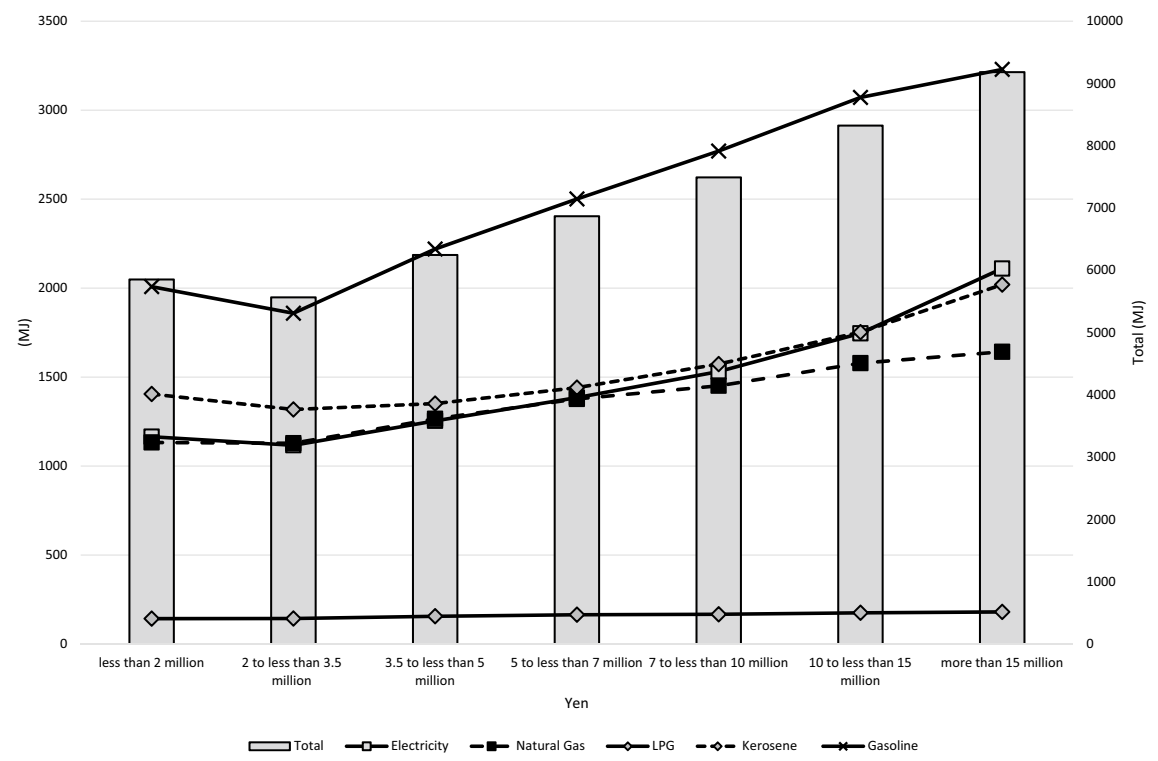

Fig. 8 Household income and energy consumption

Figure 8 shows that total energy consumption generally increases as income rises. Average energy consumption was $5853 \mathrm{MJ}$ in the lowest income group and slightly less, at $5565 \mathrm{MJ}$, in the second lowest category. Thereafter, energy use increased with income; the average monthly energy consumption of the highest income group was $9181 \mathrm{MJ}$. 
We can see that monthly consumption of each type of energy follows the same pattern as total energy consumption. This suggests that there is an overall positive relationship between household income and energy consumption for each type of energy.

Next, we discuss the relationship between household income and relative consumption of each type of energy. The data clearly show that the ratio of electricity to total energy consumption increases as income increases. In contrast, we observe an inverted U-shaped relationship between household income and the ratios of the remaining types of energy to total energy consumption. For example, the ratio of gasoline consumption to total energy consumption initially increases as household income increases, then reaches a peak when annual household income is between JPY 7-10 million. After that, the ratio starts to decline. In the case of city gas, the ratio rises initially, then starts to decrease after annual household income reaches JPY 3.5-5 million. The ratio of LP gas to total energy consumption, and also kerosene, start declining once household income reaches JPY 2.0-3.5 million. These results show that electricity dependence increases consistently as income increases, but dependence on the remaining types of energy peak, and then decline after household income reaches a certain threshold. This suggests that as their income levels rise, households allocate additional more of that income to purchase of appliances, computers and other devices that require electricity to power them. This phenomenon is not observed for LP gas, kerosene, or city gas. Indeed, high-income households consume relatively less of those types of energy compared to middle-income households. Households use these energies primarily for heating and cooking, but energy consumption for such purposes does not increase significantly with income rise.

Otsuka et al. (2013) estimated price and income elasticity of demand for electricity. When a model that includes a lag term is used, they found that short-run price elasticity was -0.483 while long-run price elasticity was -1.541 , while short-run income elasticity was estimated to be 0.086 while long-run income elasticity was 0.273 . They found that the Hokkaido region had the lowest response to price change while the Hokuriku region had the highest response. In addition, they reported that income elasticity was highest in the Kyushu region and lowest in the Kanto region. Using micro-level data from the Survey on Carbon Dioxide Emission from Households (SCDEH), Onuma et al. (2019) estimated the income elasticity of demand for electricity after controlling for appliance ownership. According to their estimates, the income elasticity of demand for electricity among Japanese households is approximately 0.07. Espey and Espey (2004) conducted a meta-analysis of 36 studies published between 1971 and 2000 and reported that short-run income elasticities ranged between 0.04 and 3.48 in previous studies. They further found that the short-run elasticity tends to be lower when controlling for appliance ownership. Their results suggest the income elasticity of Japanese households similar to that of other countries. In addition, Onuma et al. (2019) compared the price elasticity of electricity demand across different income categories and found that it has an inverted U-shaped. In other words, price elasticity increases until income rises to a certain level and then decreases. 


\subsection{Household Characteristics and Energy Consumption}

Here we examine the relationship between household characteristics and energy consumption. We focus specifically on two types of household characteristics: family composition and age of the head of household. Japan is facing a declining birth rate and aging population; in 2019 the percentage of the country's population aged 65 and older was over 28\% (Cabinet Office Japan 2019). The declining birth rate and aging population are affecting the family structure, and the proportion of married couples without children and elderly single-person households relative to all households has been increasing in recent years. Although the Japanese government has introduced various policy measures to address the problems of the declining birthrate and aging population, those policies have not yet been successful. Thus, it is important to know how household energy consumption relates to family composition and the age of the head of household.

We classify households into nine types and calculate monthly energy consumption of each type. The average energy consumption across all households was $6843 \mathrm{MJ}$ in 2014. Households composed of a couple with one child consumed an average of $6800 \mathrm{MJ}$ of energy per month, which is very close to the overall average amount. Larger households consumed much more energy. Three-generation households composed of a couple with their children and their parents consumed $9028 \mathrm{MJ}$ per month, while households composed of a couple with three or more children consumed 7544 MJ per month. Households composed of a couple with two children, or a couple with their parents consumed slightly more energy than average; the former consumed $7097 \mathrm{MJ}$ and the latter consumed $7459 \mathrm{MJ}$ per month. In contrast, consumption by single-person, single-parent, and couple-only households consumed much less energy, using $4563 \mathrm{MJ}, 5584 \mathrm{MJ}$, and $5822 \mathrm{MJ}$ per month, respectively.

It is natural to expect energy consumption to increase as household size increases. However, it is worth noting that there is an economy of scale in household energy consumption. Household members share some energy services and therefore energy consumption per capita decreases as family size increases.

The same trend was observed for energy consumption by type of energy as for total energy consumption. Single-person, couple-only, and single-parent households all consume less energy than average across all types. However, we find that households composed of a couple with children or parents consumed more kerosene than other types of households. ${ }^{14}$

The usage of each type of energy as a percent of the total energy consumption was $35-40 \%$ for gasoline and $15-25 \%$ for electricity, kerosene and city gas. However, single households tended to consume relatively more gasoline and kerosene than

\footnotetext{
${ }^{14}$ Energy consumptions of single-person household were $721 \mathrm{MJ}$ for electricity, $693 \mathrm{MJ}$ for city gas, $102 \mathrm{MJ}$ for LP gas, $1273 \mathrm{MJ}$ for kerosene, and $1775 \mathrm{MJ}$ for gasoline. Consumption for couple-only household were $1223 \mathrm{MJ}$ for electricity, $1111 \mathrm{MJ}$ for city gas, $137 \mathrm{MJ}$ for LP gas, $1332 \mathrm{MJ}$ for kerosene, and 2019 MJ for gasoline. Those of single-parent household were 1169 MJ for electricity, $1235 \mathrm{MJ}$ for city gas, $147 \mathrm{MJ}$ for LP gas, $1188 \mathrm{MJ}$ for kerosene, and $1845 \mathrm{MJ}$ for gasoline.
} 
other households. In contrast, their electricity consumption is relatively lower than in other types of households.

Next, we examine the relationship between energy consumption and the age of the head of household. We categorize households into six age groups: (1) up to 29 years old, (2) 30-39 years old, (3) 40-49 years old, (4) 50-59 years old, (5) 60-69 years old, and (6) 70 years old and older. We then calculate average monthly energy consumption for each age group.

We find that energy consumption increases from households headed by those in the youngest age groups to those in the middle age groups, then decreases from the middle to the oldest age groups. Specifically, energy consumption increases from $5245 \mathrm{MJ}$ for households where the head of household is age 29 or younger to $7437 \mathrm{MJ}$ where the head of household is age 50-59. This pattern can be explained by an individual's life cycle. Households headed by younger adults typically live in small houses and do not own many energy-consuming appliances. However, as family size increases for adults in their 30s and 40s, the number of energy-consuming appliances and the frequency of use increases. When adults are in their 50s and children typically leave the household, the family size decreases and the use of energy-consuming appliances begin to decrease.

Finally, we compare consumption of each type of energy across different head of household age groups. The result reveals that households rely on electricity and kerosene more as the age of the head of household increase. Previous studies have shown that seniors prefer warmer room temperature and use more energy for space heating, and the higher electricity and kerosene consumption by households headed by older adults reflect this. In contrast, we find that households headed by seniors consume proportionately less gasoline, city gas and LP gas than households headed by younger adults. This makes sense, as seniors tend to drive less and thus consume less gasoline. Although both city and LP gases are used for cooking, seniors cook less often than young or middle-age heads of households, explaining why gas consumption declines in households headed by seniors.

\section{Conclusion}

Although the carbon tax rate is currently low in Japan, it could be increased in the near future. A carbon tax solely based on carbon content is an economically efficient that would provide an incentive to reduce energy use, but it may impose very different burdens across regions and types of households. In this study, we used household energy consumption data from NSFE to examine (1) how household energy consumption has changed over time, (2) how energy dependence differs across regions, and (3) how energy consumption patterns vary across households. The results of our analyses reveal that the burden of a higher carbon tax based on carbon content would vary widely between regions and households.

Although households living in cold regions use more kerosene for space heating in winter time than households in warmer regions, the tax rate for kerosene had 
been set at much lower rate than for other forms of energy. If the energy tax is increased simply based on carbon content, the burden among rural households in cold regions could become much larger. Given that kerosene is indispensable for these households, countermeasures to reduce the burden would be necessary. One potential approach would be to differentiate a basic deduction based on weather conditions; the government increases the base deduction in cold regions for space heating in wintertime while it decreases it in warm regions. If such a countermeasure was applied, regional equity could be insured without increasing the pre-existing distortion of the energy tax.

We also show that although electrification has progressed among Japanese households over the past 25 years, the level of electrification differs according to household income levels. Low-income households still depend primarily on kerosene and gas and we need to carefully examine the effect of a carbon tax on the prices of these forms of energy. Previous studies in Japan have focused on electricity demand and studies that include demand for kerosene and gas are lacking. Obviously, such studies are needed.

It is expected that the average age of Japanese households will continue to increase and the size of households will shrink. Elderly people drive less and thus consume less gasoline. Therefore, an aging population will result in lower gasoline consumption. However, an aging population may increase energy consumption inside the home since elderly people spend more time at home and use more energy for space heating. Given the fact that higher income, healthy seniors are able to go out but poor and unhealthy older people are likely to stay at home, it may be necessary to reconsider the taxation of energy use at home versus energy use outside home. Finally, we confirmed that household size significantly affects energy efficiency, with smaller households exhibiting less energy efficiency. Although aging is expected to increase the number of single-person households, it may be worth considering a preferential tax treatment to encourage seniors to live with their adult children or with other seniors.

\section{Appendix}

\section{Conversion from Physical Units to Energy Units}

We converted energy consumption given in physical units to energy units (mega joules (MJ)), using the following table (Table 1). 
Table 1 Conversion from physical unit to energy unit

\begin{tabular}{l|l}
\hline Type of energy & Conversion rate \\
\hline Electricity & $3.6 \mathrm{MJ} / \mathrm{kWh}$ \\
\hline City gas & $44.8 \mathrm{MJ} / \mathrm{m}^{3}$ \\
\hline LP gas & $50.8 \mathrm{MJ} / \mathrm{kg}$ \\
\hline Kerosene & $36.7 \mathrm{MJ} / \mathrm{L}$ \\
\hline Gasoline & $34.6 \mathrm{MJ} / \mathrm{L}$ \\
\hline Light oil & $37.7 \mathrm{MJ} / \mathrm{L}$ \\
\hline
\end{tabular}

\section{References}

Cabinet Office of Japan (2009) Energy taxation etc. https://www.cao.go.jp/zei-cho/history/20092012/gijiroku/zeicho/2009/_icsFiles/afieldfile/2010/11/22/21zen9kai5.pdf. Accessed $20 \mathrm{Feb}$ 2020

Cabinet Office of Japan (2019) Annual report on the ageing society. https://www8.cao.go.jp/kou rei/english/annualreport/2019/pdf/2019.pdf. Accessed 20 Feb 2020

Espey JA, Espey M (2004) Turning on the lights: A meta-analysis of residential electricity demand elasticities. J Agric Appl Econ 36(1):65-81

Krishnamurthy CKB, Kriström B (2015) A cross-country analysis of residential electricity demand in 11 OECD-countries. Resour Energy Econ 39:68-88

Ministry of the Environment (2012) Introducing taxes for global warming countermeasures. http:// www.env.go.jp/policy/tax/about.html. Accessed 20 Feb 2020.

Mizobata M, Kanda K., Manabe Y, Oguro, Y, Suzuki J (2011) The key to addressing power shortages lies in the household sector. Daiwa Institute of Research Holdings Ltd. Economic Report

Narayana PK, Smyth R, Prasad A (2007) Electricity consumption in G7 countries: A panel cointegration analysis of residential demand elasticities. Energy Policy 35:4485-4494

Onuma H, Arimura TH, Matsumoto S (2019) How much household electricity consumption is actually saved by replacement with Light-Emitting Diodes (LEDs)? Research Institute for Environmental Economics and Management. Discussion Paper Series No.1803

Otsuka A, Taguchi YHM, Mase T (2013) An analysis of price elasticity of electric power demand in Japanese regions. Cent Res Inst Electr Power Ind. Research Paper: Y12015

Statistical Bureau of Japan. (1989-2014a). National survey of family and expenditure. http://www. stat.go.jp/english/data/zensho/index.htm. Accessed on 29 July 2017

Statistical Bureau of Japan (1989-2014b) Retail price survey. http://www.stat.go.jp/english/data/ kouri/index.htm. Accessed on 20 Oct 2018

Tanishita M (2009) Estimation of regional price elasticity of household elecricity's demand. J Jpn Soc Energy Resour 30(5):1-7

Nozomu Inoue is a demographer at National Institute of Population and Social Security since 2018. He was received the M.A. in Economics from Aoyama Gakuin University, Tokyo Japan, in 2012. He also received the B.A. in Economics from Aoyama Gakuin University. Before coming to National Institute of Population and Social Security, he was a member of the faculty of Aoyama Gakuin University.

His research interests lie in the area of regional demography and geographical information system. In his recent research, he has collaborated with Shigeru MATSUMOTO in the research on the household electricity consumption. He has contributed to the research by issuing an opinion on the time-series changes in household structure. 
Shigeru Matsumoto joined the Aoyama Gakuin University faculty in 2008. He studied on Heiwa Nakajima Foundation Scholarship at North Carolina State University, where he earned his Ph.D. in economics. He also holds his Masters of Environmental Science from Tsukuba University. Before coming to Aoyama Gakuin University, he spent seven years on the faculty of Kansai University.

His research interest lies in the applied welfare economics, with particular focus on consumer behavior analysis. In recent years, he studies households' pro-environmental behaviors such as recycling and energy-saving practices as well as consumers' valuation on food attributes such as organic farming.

http://shigeruykr.wixsite.com/happy-environment.

Minoru Morita joined the Takasaki City University of Economics faculty in 2018. He received a Ph.D. in economics from Sophia University in 2014. He also holds his Masters of Economics from Nihon University.

His research interest lies in the environmental and energy economics, with particular focus on consumer behavior analysis. Recently, he studies elderly households' energy use and behavior such as energy-saving practices in Japan.

Open Access This chapter is licensed under the terms of the Creative Commons Attribution 4.0 International License (http://creativecommons.org/licenses/by/4.0/), which permits use, sharing, adaptation, distribution and reproduction in any medium or format, as long as you give appropriate credit to the original author(s) and the source, provide a link to the Creative Commons license and indicate if changes were made.

The images or other third party material in this chapter are included in the chapter's Creative Commons license, unless indicated otherwise in a credit line to the material. If material is not included in the chapter's Creative Commons license and your intended use is not permitted by statutory regulation or exceeds the permitted use, you will need to obtain permission directly from the copyright holder.

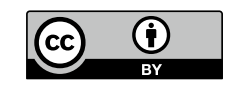

